\title{
Drainage and Cranioplasty as a Treatment for Traumatic Subdural Hygroma Secondary to Decompressive Craniectomy
}

\author{
Arun Angelo Patil1 ${ }^{*}$, Britney Bell2, Leo Yamaguchi² \\ ${ }^{1}$ Creighton University Medical Center, Omaha, USA \\ ${ }^{2}$ Creighton University School of Medicine, Omaha, USA \\ Email: *arun.patil@alegent.org
}

Received 27 October 2015; accepted 9 January 2016; published 12 January 2016

Copyright (C) 2016 by authors and Scientific Research Publishing Inc.

This work is licensed under the Creative Commons Attribution International License (CC BY). http://creativecommons.org/licenses/by/4.0/

(c) (i) Open Access

\begin{abstract}
Background: Decompressive craniectomy (DC) is performed to accommodate life-threatening brain swelling when medical treatment fails. This procedure carries the risk of developing traumatic subdural hygroma (TSH) that can adversely affect the neurological status of the patient. The treatment for persistence of TSH includes drainage and shunt placement or drainage and membranectomy. In this paper, we present treatment of two patients whose TSH was effectively treated with simple drainage and cranioplasty. Case Presentation: Patient 1: The patient is a 34-year-old female who had bilateral craniectomy for brain swelling. Four weeks later she became less interactive. CT scan showed bilateral subdural hygroma with $2 \mathrm{~cm}$ midline shift to the left. Her clinical status improved and CT scans showed resolution of the hygroma after simple evacuation of the hygroma and cranioplasty. Patient 2: The patient is a 57-year-old male who had post-traumatic acute subdural hematoma and brain swelling on the left side. The clot was evacuated and the bone flap was left out. After showing initial improvement, 10 weeks after the initial surgery the patient progressively worsened and became unresponsive. CT scans showed a large subdural hygroma on the right with midline shift to the left. Simple evacuation of the hygroma and cranioplasty was done. This resulted in radiological and clinical improvement of the patient. Conclusions: Both patients underwent simple drainage and cranioplasty, which resulted in clinical and radiological improvement. This finding suggests that other procedures such as membranectomy and shunting may not be necessary to treat TSH.
\end{abstract}

\section{Keywords}

Cranioplasty, Decompressive Craniectomy, Subdural Hygroma

\footnotetext{
${ }^{*}$ Corresponding author.
}

How to cite this paper: Patil, A.A., Bell, B. and Yamaguchi, L. (2016) Drainage and Cranioplasty as a Treatment for Traumatic Subdural Hygroma Secondary to Decompressive Craniectomy. Open Journal of Modern Neurosurgery, 6, 41-44. 


\section{Introduction}

Control of intracranial pressure (ICP) in order to maintain adequate cerebral perfusion pressure (CPP) is critical in the management of traumatic brain injury (TBI). Even with aggressive medical treatment such as hyperosmolar dehydration, hyperventilation, and barbiturate coma in approximately 10\% - 15\%, a safe level of CPP cannot be maintained. In such a situation decompressive craniectomy (DC) is one of the treatment options [1]-[11]. Although DC effectively lowers intracranial pressure in $80 \%$ of cases, it can result in expansion of hemorrhagic contusions, external cerebral herniation, post-traumatic hydrocephalus, delayed paradoxical herniation, bone resorption, loss of function and traumatic subdural hygroma (TSH) formation [12]-[20]. Various treatment modalities have been used to treat TSH. They include: evacuation of the hygroma and shunt placement. There is also a reported case in which membranectomy followed by cranioplasty was done with complete resolution of the hygroma [20]-[22]. In this paper the authors illustrate 2 cases in which cranioplasty with simple drainage of the hygroma was adequate to treat TSH.

\section{Case Presentation}

Case 1: A 34-year-old female sustained a TBI after she fell out of a car. She was combative at the scene of the accident and moved her 4 extremities. CT scans of the head showed a moderate sized epidural clot. The clot increased in size leading to deterioration of her neurological condition. The clot was evacuated through a craniotomy, and the patient's condition stabilized. Six days later, her condition worsened. CT scans showed diffuse brain swelling so a bilateral decompressive craniectomy was performed. Her condition progressively got better; however, 4 weeks later she became less interactive. CT scans showed a bilateral subdural hygroma (Figure 1(a)), which was larger on the right with a $2 \mathrm{~cm}$ shift of the midline to the left. The patient was consequently taken to the operating room for cranioplasty using patients freezer stored bone. During reflection of the scalp from the dura, the dura got torn and most of the hygroma fluid leaked out. The dural defect was covered with Dura Gen (manufactured by Integra, Plainsboro, New Jersey, USA), the bone flap was put back and the scalp was closed. After the surgery she progressively improved. Condition progressively improved, and at three months follow-up on gross neurological examination, no deficit was detected. Post-operative scans done 6 weeks after the operation showed almost complete resolution of the midline shift and subdural hygroma.

Patient 2: A 57-year-old male had TBI following a motorcycle accident. On admission he was combative and moved all 4 extremities spontaneously. CT scans of the head showed right-sided acute subdural hematoma with a midline shift. The subdural hematoma was evacuated, but the bone flap was not put back because of significant brain swelling. Two weeks later, the swelling had decreased and the patient showed an improved neurological status by following commands. Ten weeks after the initial surgery, the patient progressively worsened and became unresponsive. CT scans showed a large subdural hygroma with midline shift to the right (Figure 2(a) \& Figure 2(b)). The wound was then opened, the hygroma fluid was drained out, and cranioplasty was performed. A CT scan 2 weeks later showed almost complete resolution of the hygroma (Figure 2(c)) and improvement in neurological status.

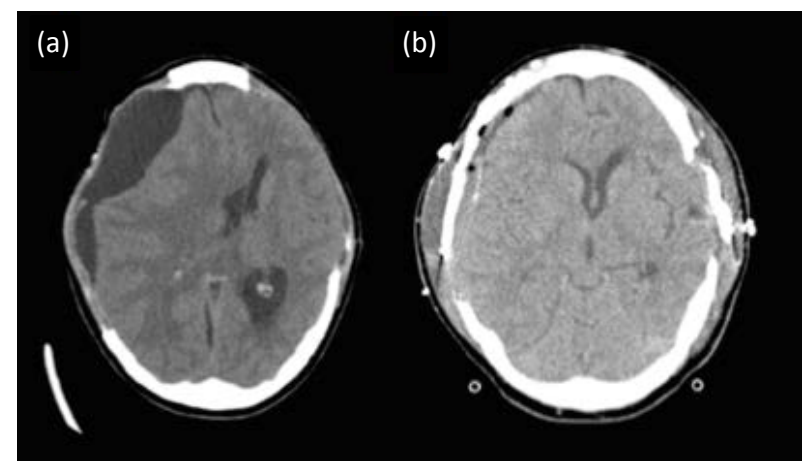

Figure 1. (a) CT image show bilateral craniectomy, large subdural hygroma right and midline shift to the left. (b) CT image after 6 weeks after bilateral cranioplasty shows almost complete resolution of the hygroma on the right. 


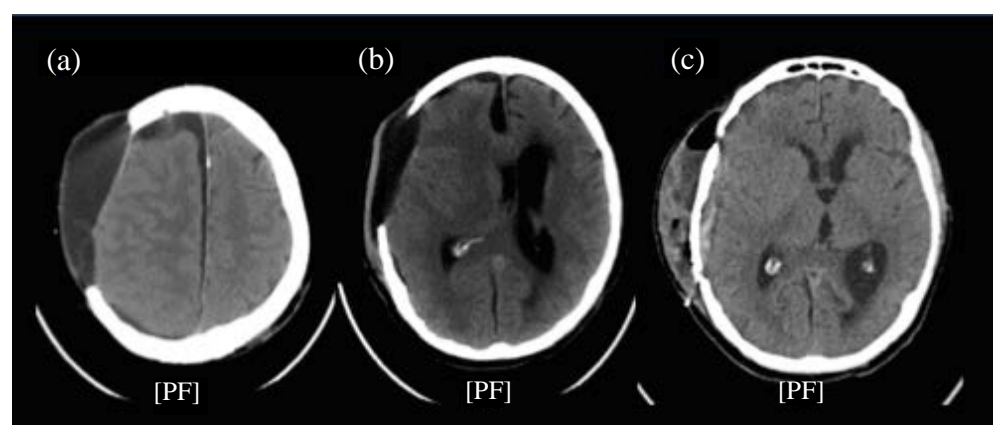

Figure 2. (a) \& (b) CT images show right side craniectomy, collection of subdural hygromaand midline shift to the left. (c) CT image 2 weeks after cranioplasty shows almost complete resolution of the subdural hygroma and midline shift.

\section{Discussion}

A subdural collection of cerebrospinal fluid is usually referred to as a traumatic subdural hygroma (TSH), which is also referred to as a Traumatic Subdural Effusion (TSE) or External Hydrocephalus (EHP) [20]-[22]. Most reports do not distinguish between a TSH and a subdural effusion because protein content in the fluid is generally not measured at the time of extraction. For clarity purposes, we will utilize the definition of TSH established by Miranda et al.; a TSH occurs if the protein contents of the fluid are similar to CSF and a subdural 76effusion occurs if the protein content is higher than CSF [22].

Although there is no conclusive evidence for or against DC being beneficial, this procedure is widely performed as a last resort in patients who develop uncontrolled intracranial pressure. However, DC is associated with many potential risks, including the risk for TSH. Approximately $7 \%-12 \%$ of patients with severe traumatic brain injuries develop TSH. Aarabi et al. have described the natural history of TSH as appearing the first week, peeking by the 4th week, and in most cases, disappearing by the 17th week. The chances of developing a TSH after a DC is performed rises to $21 \%$ - 50\% according to Paredes et al. Although TSH develops in a high percentage of patients after a DC, surgical evacuation was needed in only $10 \%$ [2].

The development of TSH secondary to DC is not completely understood; however, there are several theories that have been proposed to explain the pathophysiological basis for its development. They include a tear in the arachnoid with uni-directional CSF flow in the subdural space, effusion due to vascular and or parenchymal injury, and increased arachnoid permeability due to physical disruption of high transmembrane pressure [19] [20].

According to Waziri et al. [23] DC flattens the dicrotic ICP wave. This would decrease CSF flow across the arachnoid granulation into the venous sinuses resulting in accumulation in the subdural space. Placement of cranioplasty probably reverses the effect and corrects the problem with resolution of the hygroma.

\section{Conclusion}

In summary, 2 patients with TSH are presented who both showed improvement in their neurological status and radiological findings following drainage of the hygroma fluid and cranioplasty. These findings suggest that other procedures such as membranectomy and shunting may not be necessary to treat TSH.

\section{References}

[1] Kunze, E., Meixensberger, J., Janka, M., Sorensen, N. and Roosen, K. (1998) Decompressive Craniectomy in Patients with Uncontrollable Intracranial Hypertension. Acta Neurochirurica (Supplement), 71, 16-18. http://dx.doi.org/10.1007/978-3-7091-6475-4_5

[2] Aarabi, B., Hesdorffer, D.C., Ahn, E.S., Aresco, C., Scalea, T.M. and Eisenberg, H.M. (2006) Outcome Following Decompressive Craniectomy for Malignant Swelling Due to Severe Head Injury. Journal of Neurosurgery, 104, 469479. http://dx.doi.org/10.3171/jns.2006.104.4.469

[3] Schneider, G.H., Bardt, T., Lanksch, W.R. and Unterberg, A. (2002) Decompressive Craniectomy Following Traumatic Brain Injury: ICP, CPP and Neurological Outcome. Acta Neurochirurica (Supplement), 81, 77-79. http://dx.doi.org/10.1007/978-3-7091-6738-0_20 
[4] Skoglund, T.S., Eriksson-Ritzen, C., Jensen, C. and Rydenhag, B. (2006) Aspects on Decompressive Craniectomy in Patients with Traumatic Head Injuries. Journal of Neurotrauma, 23, 1502-1059. http://dx.doi.org/10.1089/neu.2006.23.1502

[5] Cooper, D.J., et al. (2011) Decompressive Craniectomy in Diffuse Traumatic Brain Injury. New England J Medicine, 364, 1493-1502. http://dx.doi.org/10.1056/NEJMoa1102077

[6] Al-Jishi, A., Saluja, R.S., Al-Jehani, H., Lamoureux, J., Maleki, M. and Marcoux, J. (2011) Primary or Secondary Decompressive Craniectomy: Different Indication and Outcome. Canadian Journal of Neurological Sciences, 38, 612620. http://dx.doi.org/10.1017/S0317167100012154

[7] Stiver, S.I. (2009) Complications of Decompressive Craniectomy for Traumatic Brain Injury. Neurosurgical Focus, 26, E7. http://dx.doi.org/10.3171/2009.4.FOCUS0965

[8] Yang, X.J., Hong, G.L., Su, S.B. and Yang, S.Y. (2008) Complications Induced by Decompressive Craniectomies after Traumatic Brain Injury. Chinese Journal of Traumatology, 6, 99-103.

[9] Honeybul, S. and Ho, K.M. (2012) Incidence and Risk Factors for Post-Traumatic Hydrocephalus Following Decompressive Craniectomy for Intractable Intracranial Hypertension and Evacuation of Mass Lesions. Journal of Neurotrauma, 29, 1872-1878. http://dx.doi.org/10.1089/neu.2012.2356

[10] Honeybul, S., Ho, K.M., Lind, C.R. and Gillett, G.R. (2010) Decompressive Craniectomy for Neurotrauma: The Limitations of Applying an Outcome Prediction Model. Acta Neurochirurgica (Wien), 152, 959-964. http://dx.doi.org/10.1007/s00701-010-0626-5

[11] Kilincer, C. and Hamamcioglu, M.K. (2010) Surgical Complications of Decompressive Craniectomy for Head Trauma. Acta Neurochirurgica, 152, 557-558. http://dx.doi.org/10.1007/s00701-009-0476-1

[12] Lee, K.S. (1998) The Pathogenesis and Clinical Significance of Traumatic Subdural Hygroma. Brain Injury, 12, 595603. http://dx.doi.org/10.1080/026990598122359

[13] Lee, K.S., Bae, W.K., Bae, H.G. and Yun, I.G. (2000) The Fate of Traumatic Subdural Hygroma in Serial Computed Tomographic Scans. Journal of Korean Medical Science, 15, 560-568. http://dx.doi.org/10.3346/jkms.2000.15.5.560

[14] Aarabi, B., Chesler, D., Maulucci, C., Blacklock, T. and Alexander, M. (2009) Dynamics of Subdural Hygroma Following Decompressive Craniectomy: A Comparative Study. Neurosurgical Focus, 26, E8. http://dx.doi.org/10.3171/2009.3.FOCUS0947

[15] Margules, A. and Jallo, J. (2010) Complications of Decompressive Craniectomy. JHN Journal, 5, Article 4.

[16] Paredes, I., Cicuendez, M., Delgado, M.A., Martinez-Pérez, R., Munarriz, P.M. and Lagares, A. (2011) Normal Pressure Subdural Hygroma with Mass Effect as a Complication of Decompressive Craniectomy. Surgical Neurology International, 2, 88. http://dx.doi.org/10.4103/2152-7806.82370

[17] Yang, X.F., Wen, L., Li, G., Zhan, R.Y., Ma, L. and Liu, W.G. (2009) Contralateral Subdural Effusion Secondary to Decompressive Craniectomy Performed in Patients with Severe Traumatic Brain Injury: Incidence, Clinical Presentations, Treatment and Outcome. Medical Principles and Practice, 18, 16-20. http://dx.doi.org/10.1159/000163040

[18] Yang, X.F., Wen, L., Shen, F., Li, G., Lou, R., Liu, W.G., et al. (2008) Surgical Complications Secondary to Decompressive Craniectomy in Patients with a Head Injury: A Series of 108 Consecutive Cases. Acta Neurochirurgica, 150, 1241-1247. http://dx.doi.org/10.1007/s00701-008-0145-9

[19] Zanini, M.A., de Lima Resende, L.A., de Souza Faleiros, A.T. and Gabarra, R.C. (2008) Traumatic Subdural Hygromas: Proposed Pathogenesis Based Classification. Journal of Trauma, 64, 705-713. http://dx.doi.org/10.1097/TA.0b013e3180485cfc

[20] Zanini, M.A., Resende, L.A., Freitas, C.C. and Yamashita, S. (2007) Traumatic Subdural Hygroma: Five Cases with Changed Density and Spontaneous Resolution. Arquivos de Neuro-Psiquiatria, 65, 68-72. http://dx.doi.org/10.1590/s0004-282x2007000100015

[21] Tzerakis, N., Orphanides, G., Antoniou, E., Sioutos, P.J., Lafazanos, S. and Seretis, A. (2010) Subdural Effusions with Hydrocephalus after Severe Head Injury: Successful Treatment with Ventriculoperitoneal Shunt Placement: Report of 3 Adult Cases. Case Reports in Medicine, 2010, Article ID: 743784.

[22] Miranda, P., Lobato, R.D., Rivas, J.J., Alen, J.F. and Lagares, A. (2004) Postraumatic Subdural Collections: Case Report and Review of the Literature. Neurocirugia, 15, 67-71. http://dx.doi.org/10.1016/S1130-1473(04)70503-5

[23] Waziri, A., Fusco, D., Mayer, S.A., McKhann, G.M. and Connolly Jr., E.S. (2007) Postoperative Hydrocephalus in Patients Undergoing Decompressive Hemicraniectomy for Ischemic or Hemorrhagic Stroke. Neurosurgery, 61, 489-493. http://dx.doi.org/10.1227/01.NEU.0000290894.85072.37 